\title{
India's Ageing Population: Geriatric Care Still in Infancy
}

\author{
Mane Abhay $\mathrm{B}^{1^{*}}$, Khandekar Sanjay $\mathrm{V}^{2}$ and Kevin Fernandez VSM ${ }^{1}$ \\ ${ }^{1}$ Department of Community Medicine, Smt. Kashibai Navale Medical College, Pune, Maharashtra, India \\ ${ }^{2}$ Department of Community Medicine, Ashwini Rural Medical College, Solapur, Maharashtra, India
}

"Corresponding author: Mane Abhay B, Department of Community Medicine, Smt. Kashibai Navale Medical College, Narhe, Pune, Maharashtra, India, Tel: +918975008663, 020-24106274; E-mail: drabmane@yahoo.co.in

Rec date: Nov 20, 2014; Acc date: Nov 25, 2014; Pub date: Nov 27, 2014

Copyright: (c) 2014 Mane Abhay B, et al. This is an open-access article distributed under the terms of the Creative Commons Attribution License, which permits unrestricted use, distribution, and reproduction in any medium, provided the original author and source are credited.

\begin{abstract}
Healthy ageing is a major public health challenge. The population of India is ageing. This demographic change will necessitate vast resources towards support, care and treatment of elder persons. With the changes in the social scenario and the emergence of nuclear family concept have exposed the elderly people to emotional, physical and financial insecurity. The prevalence and incidence of diseases as well as hospitalization rates are much higher in older people than the total population. Very little effort has been made to understand the health and social care needs of elderly in India. Moreover there is a huge shortage of manpower in geriatrics in the country and this does not seem to improve in very near future. The undergraduate medical curriculum at present does not cover geriatric care completely, while postgraduate geriatric courses are almost absent in India. Making the resources available and capacity building of the staff involved in geriatric care will be a herculean task. Also the other health problems in India and their priorities may push the interest of the older people into the background. The problems and issues of its greying population occupy the back-seat. If we do not address the ground realities with regard to geriatrics, the elderly will not age gracefully. This article highlights the plight of the Indian elder with respect to the changing demographics and assesses the status of geriatric care.
\end{abstract}

Keywords: Ageing; Elderly; Geriatric care; Health problems; NPHCE

\section{Introduction}

Ageing is a global demographic phenomenon. India is no exception to this due to successful development in medical sciences and technology, living standards, and education. As per the World Health Statistics 2011, 83 million people in India are 60 years of age and older, representing over $7 \%$ of the nation's total population [1]. As per the projections, India's demographic structure is expected to shift dramatically from a young to an aging population resulting in 316 million elderly persons by 2050 [2]. The current demographic trend is predicted to continue in the future also. The demographic challenges of ageing are likely to be most pronounced as the basic and essential geriatric care is simply not available. With increased life expectancy, comes more complex diseases of ageing that are harder and more costly to manage. The aging population is not only a medical problem but also a sociological problem. Hence the practical implications of the population aging for India are far reaching and will pose various challenges in handling them. In fact, geriatric health issues are identified as one of the top five challenges that primary health care will face in the coming years [3]. This review paper is a modest attempt to describe the demographics, health problems, challenges and current policies and scenario of geriatric care in India

\section{Demographic profile and projections of elderly}

The global projection of geriatric population by 2025 is that the elderly population is expected to rise by more than 1.2 billion. Out of these, about 840 million elderly will be living in developing countries [4]. As per the Sample Registration System (SRS) (2012) in India, the population of persons above 60 year is $8.3 \%$ of the total population [5].
The projected geriatric population will be 195 million by the year 2030 and further estimated to be 308 million by the year 2050, constituting about $20 \%$ of the total population [6]. The population over the age of 60 years has tripled in last 50 years in India and will relentlessly increase in near future. The proportion of older people which was $8.14 \%$ in 2011 is likely to increase to $8.94 \%$ in 2016 [6]. The life expectancy at birth is also increasing consistently making a large number of people to live longer than before. The projected data on life expectancy at birth from 2001-2006 were 63.87 and 65.43 for males and females respectively. The figures of life expectancy at birth from 2011-2016 will also rise to 67.04 and 68.8 years for males and females respectively [7]. The Non-communicable diseases that require large amount of health and social care are extremely common in old age and found in elderly from all socio-economic strata. Also the disabilities due to these non-communicable diseases are frequently affecting the functionality of the elderly and their ability to pursue the activities of daily living. Hence the management of these chronic diseases becomes costly and most of it is out-pocket expenses. To add to the woe is the decrease in income post retirement and more so for the elderly in the unorganized sector and dependent elderly women. The National Sample Survey of 2004 (60th Round) [8] points out that the prevalence and incidence of diseases as well as hospitalization rates are much higher in older people than the total population. It also reported that about $8 \%$ of older Indians were confined to their home or bed.

\section{Health problems of the elderly}

The health problems of the elderly can be grouped broadly as those due to ageing process, problems associated with long-term illness and psychological problems. The declining health status and decreased functional capacity due to aging process primarily depends on heredity, lifestyles, and the nutritional quality of foods consumed 
daily. Apart from geriatric conditions seen specifically in these populations, the average elder in India suffers from dual set of communicable and non-communicable conditions. The most common chronic conditions seen in India are diabetes, hypertension and cardiovascular diseases. The ageing Indian population that is suffering from chronic conditions puts an incredible amount of burden on the already stretched health care system [9]. Also most of the elderly in India suffer from more than one disability at a time. The common and multiple disabilities seen are cardiovascular diseases, visual and hearing impairments, respiratory disorders, depression, and infections like tuberculosis [10]. Studies have shown that among the population over 60 years of age, $10 \%$ are hospitalized at any given time, $10 \%$ suffer from impaired physical mobility and both proportions rise with increasing age [11]. In the Population over 70 years of age, more than $50 \%$ suffer from one or more chronic conditions [12]. A recent data published by Government of India on elderly shows that one-third of elderly mortality is attributed to cardiovascular disorders. $10 \%$ of the mortality is due to respiratory disorders and infections including tuberculosis account for $10 \%$ mortality among them. Neoplasm accounts for $6 \%$, while accidents, violence and poisoning together constitute less than $4 \%$ of mortality among the elderly in India [13]. Also the morbidity data of elderly varies not only with regions but also from time to time as noted by many studies [13-15]. Malnutrition, occult hypothyroidism, renal failure, depression and sexual problems are also common in the elderly. In a community based study conducted in Delhi among 10,000 elderly people, it was found that problems related to vision and hearing topped the list, closely followed by backache and arthritis [16]. In a study conducted at a tertiary care centre in New Delhi among 206 elderly persons attending the Geriatric Clinic, about $34 \%$ and $40.3 \%$ of the men and women were obese respectively [17]. The mental disorders that are frequently encountered in Indian elderly include dementia and mood disorders. The other mental disorders seen are neurotic and personality disorders, alcohol and drug abuse, delirium, and psychosis [17]. This has been attributed to rapid urbanization and modernization of the society with resultant breakdown in family values and the framework of family support, social isolation, economic insecurity and abuse of the elderly. The socio-economic problems of the elderly are aggravated by factors such as the lack of social and economic security. Many surveys have shown that retired elderly people are confronted with the problems of loneliness and financial insecurity [18,19]. The elderly are also prone to abuse in an institutional setting and also in their families. This may include physical, psychological or emotional abuse [20].

\section{Challenges for geriatric care}

The dramatic social, demographic and economic shifts in India have created an urgent need for good quality medical and social care for the nation's elders. However, the challenges are meeting the needs of an aging population in a resource constrained environment characterized by limited awareness, knowledge and research in geriatrics. But very little effort has been made to develop a model of health and social care in tune with the changing need and time. The requirements for health care of the elderly are also different for India due to the uniqueness of elderly population. At present most of the elderly receive health care by the public health care system in the country. The infrastructure is grossly deficient and the staff is not sensitized or trained for geriatric care at the primary care level in the public health system. Moreover, the health system is geared up to deal with the maternal and child health and communicable diseases; not for elderly care. The Indian elderly as stated suffer from chronic diseases and co-morbid conditions that need continuum care. Their health problems also need multi-disciplinary specialist care from various disciplines e.g. orthopedics, dental, ophthalmology, cardiovascular, psychiatry and urology. Thus a model of care providing comprehensive health services to elderly at all levels of health care delivery is imperative to meet the growing health care needs of the elderly. This care has to be provided close to their homes as many of them are immobile and disabled. Since majority of the elderly reside in rural areas, reaching out to each of them for care based on the principles of primary health care will be highly challenging task in a diverse set up of the country. A majority of them (80\%) are in staying in the rural areas and $30 \%$ of them are below poverty line makes the health care service delivery challenging $[6,11]$. Elderly health care in most cases is part of the general public health care system in India. As the elderly suffer from co-morbid chronic and disabling conditions making it difficult for them get timely and appropriate health care. The undergraduate medical curriculum does not cover all aspects of geriatric care adequately. Postgraduate geriatric courses are grossly inadequate in the country. There is a definite need to emphasize the fact that disease and disability are not part of old age as routinely believed and timely help must be sought to address the health problems. Also the concept of healthy ageing needs to be promoted not only among the elderly but also among the younger age groups. The healthy ageing should include comprehensive promotional, preventive and rehabilitative aspects of health. It has been estimated that almost more than half of the aged persons are fully dependent on others for economical reasons [21]. Hence any attempt to improve the quality of geriatric care and outcomes in India must address or take into account the financial barriers to access the health care.

At present, most of the geriatric outpatient department (OPD) services are available at tertiary care hospitals in India. Since most of the elderly reside in rural areas, it is utmost desirable that geriatric health care services should be a part of the primary health care services provided by the Government. This calls for the attention to the training of medical officers, paramedical and support staff in geriatric medicine [22]. Also the evidence based research in Geriatrics and Gerontology is abysmal and needs to be further encouraged. In the World, India will soon become home to the second largest number of elderly people. The challenges are unique with this population particularly in the Indian context.

\section{Current scenario of geriatric care}

Nearly $60 \%$ of older people are said to have hearing impairment in both urban and rural areas. Most of the geriatric outpatient department (OPD) services are available at tertiary care hospitals concentrated in urban areas. Also, most of the facilities such as old age residential homes, day care centers and other facilities like counseling and recreation are urban based. In a study conducted to assess the unmet needs of the geriatric population in rural Meerut revealed that $46.3 \%$ of the elderly were unaware of the availability of any geriatric services near their residence. Almost all of them (96\%) had never used any geriatric welfare services till the time of survey. More than half (59\%) of them said that the nearest government health facility was about 3 kilometers away from their homes [19].

The National Programme for Health Care for the Elderly (NPHCE) is implemented from 2011 by the Ministry of Health and Family Welfare, Government of India to address the issue of geriatric care by introducing a comprehensive health care set up that is completely 
dedicated and tuned to the needs of the elderly [6,7]. As per NPHCE, it is envisaged to provide comprehensive promotional, preventive, curative and rehabilitative services in an integrated manner for the elderly in various Government health facilities. The package of services is based on the level of health facility, but also varies from type of facility. These services are made available by (1) expanding infrastructure from community-based geriatric clinics to include geriatric units in district hospitals and establishing the Regional Geriatric Centres; (2) establishing specialized geriatric training programs and research institutes; and (3) utilizing mass media to educate the public. An old age pension scheme has been introduced by the Government to meet the needs of the elderly who have no means to support themselves. The Government and social policies for the elderly in India have also grown and include old age pensions, the National Policy for Older Persons (1999), the National Initiative on Care for the Elderly (2004), and the recent Maintenance and Welfare of Parents and Senior Citizens Act (2007) [23]. The shortage in man power for geriatric care is unaddressed even today as only 4 medical colleges have a post graduation in geriatrics with an annual intake of 7 seats [24]. The efforts to provide geriatric care by Government and other Non Governmental Organizations (NGO) tend to be uncoordinated, relying heavily on the NGOs that are unevenly distributed across India. Health care providing organizations and individual care providers often fail to prioritize elderly patients and have limited resources to manage the chronic conditions in elderly [25]. Some of the facilities are dedicated to geriatric care; but are concentrated in urban areas and are prohibitively expensive for most of the elderly [26]. The criticism against the Government and private hospitals is that they lack the capacity to provide the comprehensive geriatric care to the elderly [26]. Even some hospitals are providing geriatric outpatient services, but do not have geriatric inpatient facilities separately. Further to state that the day-care centres, old-age homes and mobile medical units are very few and available mostly in urban areas [27]. Most of them are focused on tertiary care than to primary care, hence expensive and leave many of the elderly without appropriate healthcare that is needed [28]. The need of the hour is to educate and train more healthcare providers in geriatrics. Also to develop geriatric services that shall be made operational through the existing primary healthcare system focusing not only urban areas but also in rural India.

\section{Conclusion}

The elderly population in India has longevity on one hand to cheer and a compromised quality-of-life on the other. As India ages, the task for National Government and health services will be to provide care for citizens that are living longer but doing so in fragile health. The rapid demographic shifts will have dramatic implications for health providers around the world and particularly in India. Hence it is high time that the health care system gears itself to growing health needs of the elderly in a comprehensive manner. Governments and health care providers are in a race against time to beef up the comprehensive geriatric care. The time will decide if they will be able to meet the even faster pace at which their citizens are reaching an age or condition where they need those services. The current policies and strategies undertaken by the Government of India are grossly inadequate to deal with the multi-dimensional physical, psychological, and emotional needs of the ageing population. For improving the quality-of-life of the elderly, we need a holistic approach and integrated efforts by the health and other health-related sectors in India to make an impact on geriatric care.

\section{Acknowledgement}

The authors are thankful to Dr A.V. Bhore, Dean, Smt. Kashibai Navale Medical College, Pune, Maharashtra, India for his valuable guidance and support for this review.

\section{References}

1. WHO (2011) World health statistics. Geneva: WHO.

2. James KS (2011) India's demographic change: opportunities and challenges. Science 333: 576-580.

3. WHO (2008) Primary health care: Indian scenario. Geneva: WHO.

4. WHO (2002) Tufts University School of Nutrition and Policy. Keep fit for life: Meeting the nutritional needs of older persons. WHO, Geneva.

5. Government of India (2013) Sample Registration System Statistical report 2012. Office of the Registrar General, India, Ministry of Home Affairs, Government of India, New Delhi.

6. Government of India (2011) National programme for the healthcare of the elderly: an approach towards active and healthy ageing.

7. Raina SK (2013) National Programme for the Health Care for the Elderly (NPHCE): Are we doing enough? International Journal of Clinical Cases and Investigations 5: 33-38.

8. Government of India (2006) Morbidity, health care and the condition of the aged. National Sample Survey Organization 60th round (January June 2004).

9. Dele Abegunde Anderson Stanciole (2006) WHO. An estimation of the economic impact of chronic noncommunicable diseases in selected countries.

10. Government of India (2003) Summary - report on causes of death: 2001-2003 in India.

11. Ingle GK, Nath A (2008) Geriatric health in India: concerns and solutions. Indian J Community Med 33: 214-218.

12. Reddy PH (1996) The health of the aged in India. Health Transit Rev 6 Suppl: 233-244.

13. Guha R (1994) Morbidity Related Epidemiological Determinants in Indian Aged - An Overview. In: Ramachandran CR, Shah B, (eds). Public Health Implications of Ageing in India. New Delhi: Indian Council of Medical Research.

14. Shah B, Prabhakar AK (1997) Chronic morbidity profile among elderly. Indian J Med Res 106: 265-272.

15. Purty AJ, Bazroy J, Kar M, Vasudevan K, Veliath A, et al. (2006) Morbidity Pattern among the elderly population in the rural area of Tamil Nadu, India. Turk J Med Sci 36: 45-50.

16. Dey AB, Soneja S, Nagarkar KM, Jhingan HP (2001) Evaluation of the health and functional status of older Indians as a prelude to the development of a health programme. Natl Med J India 14: 135-138.

17. Singh P, Kapil U, Dey AB (2004) Prevalence of overweight and obesity amongst elderly patients attending a geriatric clinic in a tertiary care hospital in Delhi, India. Indian J Med Sci 58: 162-163.

18. Bhatia HS (1983) Ageing and society: A sociological study of retired public servants. Udaipur: Arya's Book Centre Publishers.

19. Goel PK, Garg SK, Singh JV, Bhatnagar M, Chopra H, et al. (1999) Unmet needs of the elderly in a rural population of Meerut. Indian J Community Med 28:165-6.

20. Chokkanathan S, Lee AE (2005) Elder mistreatment in urban India: a community based study. J Elder Abuse Negl 17: 45-61.

21. Subramanya RKA (1994) Income security for the elderly in India. Bold, Quarterly Journal of India (UN) 4: 28-9.

22. Yeolekar ME (2005) Elderly in India--needs and issues. J Assoc Physicians India 53: 843-844.

23. Evans JM, Kiran PR, Bhattacharyya OK (2011) Activating the knowledgeto-action cycle for geriatric care in India. Health Res Policy Syst 9: 42.

24. http://www.mciindia.org/InformationDesk/CollegesCoursesSearch.aspx. 
Citation: Mane Abhay B, Khandekar Sanjay V, Kevin Fernandez VSM (2014) India's Ageing Population: Geriatric Care Still in Infancy. J Gerontol Geriatr Res 3: 1000186. doi:10.4172/2167-7182.1000186

Page 4 of 4

25. Krishnaswamy B, Sein U, Munodawafa D, Varghese C, Venkataraman K et al. (2008) Ageing in India. Ageing International 32: 258-68.

28. Dhar HL (2005) Emerging geriatric challenge. J Assoc Physicians India 53: $867-872$.

26. Gangadharan KR (2003) Geriatric hospitals in India, today and in the future. J Aging Soc Policy 15: 143-158.

27. Kumar V (2003) Health status and health care services among older persons in India. J Aging Soc Policy 15: 67-83. 